\title{
Amino Acid Synthesis Is Necessary for Tomato Root Colonization by Pseudomonas fluorescens Strain WCS365
}

\author{
Marco Simons, Hjalmar P. Permentier, Letty A. de Weger, Carel A. Wijffelman, and Ben J. J. \\ Lugtenberg \\ Leiden University, Institute of Molecular Plant Sciences, Clusius Laboratory, Wassenaarseweg 64, $2333 \mathrm{AL}$ \\ Leiden, The Netherlands; Tel. (+31) 71 5275063; Fax. (+31) 715275088 \\ Received 17 June 1996. Accepted 30 October 1996.
}

In this work the bio-availability of amino acids for the root-colonizing Pseudomonas fluorescens strain WCS365 in the tomato rhizosphere was studied. The amino acid composition of axenically collected tomato root exudate was determined. The results show that aspartic acid, glutamic acid, isoleucine, leucine, and lysine are the major amino acid components. The concentrations of individual amino acids in the rhizosphere of gnotobiotically grown tomato plants were estimated and considered to be too low to support growth of rhizosphere micro-organisms to numbers usually found in the tomato rhizosphere. To test this experimentally, mutants of P. fluorescens WCS365 auxotrophic for the amino acids leucine, arginine, histidine, isoleucine plus valine, and tryptophan were isolated after mutagenesis with Tn5lacZ. Root tip colonization of these mutants was measured after inoculation of germinated tomato seeds and subsequent growth in a gnotobiotic quartz sand system (M. Simons, A. J. van der Bij, I. Brand, L. A. de Weger, C. A. Wijffelman, and B. J. J. Lugtenberg. 1996. Gnotobiotic system for studying rhizosphere colonization by plant growth-promoting Pseudomonas bacteria. Mol. Plant-Microbe Interact. 9:600-607). In contrast to the wild-type strain, none of the five amino acid auxotrophs tested was able to colonize the tomato root tip, neither alone nor after co-inoculation with the wild-type strain. However, addition of the appropriate amino acid to the system restored colonization by the auxotrophic mutants, usually to wild-type levels. Analysis of the root base showed that cells of auxotrophic mutants were still present there. The results show that, although amino acids are present in root exudate, the bio-availability of the tested amino acids is too low to support root tip colonization by auxotrophic mutants of $P$. fluorescens strain WCS365. The genes that are required for amino acid synthesis are therefore necessary for root colonization. Moreover, these compounds apparently play no major role as nutrients in the tomato rhizosphere.

Since the numbers of micro-organisms on plant roots are

Corresponding author: Ben J. J. Lugtenberg

E-mail: Lugtenberg@ rulsfb.leidenuniv.nl usually higher than in distant soil (Hiltner 1904), the plant root is thought to be the major source of nutrients for microorganisms living in the rhizosphere (Lynch and Whipps 1990). Therefore, bacterial growth on compounds present in the rhizosphere is assumed to be essential for efficient colonization of and establishment in the rhizosphere. Despite the importance of bacterial growth in the rhizosphere, hardly anything is known about bacterial nutrition in this complex niche. Identification of the exudate nutrients and their utilization by rhizosphere microbes is therefore a key to unraveling the microbial competition for nutrients in the rhizosphere.

Amino acids, sugars, and organic acids are quantitatively the major components of root exudate, which is supposed to be the major source of nutrients for rhizosphere-colonizing micro-organisms. Knowledge of the bacterial growth conditions in the rhizosphere is important for understanding rhizosphere colonization. This in turn is critical for the application of beneficial micro-organisms as inoculants to support plant growth (Schippers et al. 1987; Weller 1988). A few years ago we initiated a study to elucidate the molecular basis of rhizosphere colonization by Pseudomonas bacteria. Our approach was to predict bacterial traits that might be involved in colonization. After mutants defective in such traits were isolated, the hypothesis was tested by analyzing the colonization ability of these mutants in comparison with that of the wild type. In this way it was shown that the presence of flagella (de Weger et al. 1987) and the presence of the O-antigen of lipopolysaccharide (de Weger et al. 1989) are important colonization traits. More recent results indicate that the ability to synthesize vitamin B1 and a high growth rate are also important colonization traits (Simons et al. 1996). In this paper we focused on the bio-availability of amino acids for the efficient tomato root-colonizing $P$. fluorescens strain WCS365, and on their role in colonization. We determined the amino acid composition of axenically collected tomato root exudate and the ability of newly isolated amino acid auxotrophic Tn5lacZ mutants to colonize the roots.

\section{RESULTS}

Analysis of tomato root exudate.

Tomato root exudate was collected from 80 sterile 7-dayold tomato plantlets grown in $80 \mathrm{ml}$ of sterile PNS. After 
samples from the exudate were shown to not show microbial growth, amino acids were isolated by trapping them on a Dowex AG50W8 ion exchange column. After derivatization with PITC, the amino acids were analyzed by high-performance liquid chromatography (HPLC), as described in Materials and Methods. Based on the elution profiles of mixtures of standard amino acids and exudate samples, exudate amino acids were identified and quantified after correction for losses during the sample preparation, which were determined individually for each amino acid. Amino acids that were not detected were therefore apparently absent or present below the detection limit of approximately $1 \mu \mathrm{M}$ in exudate. Detection could not be improved by further sample concentration since this procedure resulted in the appearance of background peaks. Data is shown in Table 1. Aspartic acid, glutamic acid, isoleucine, leucine, and lysine appeared to be the major amino acids. Amino acids not found in exudate are alanine, proline, tyrosine, valine, methionine, and cysteine. The results show that the amounts exuded in 1 week per plant are in the nanomole range.

Based on these data we attempted to estimate the amino acid concentrations in the rhizosphere assuming that (i) the average root length is $80 \mathrm{~mm}$, (ii) the average root diameter is $1 \mathrm{~mm}$, (iii) the average rhizosphere thickness is $1 \mathrm{~mm}$, (iv) the secreted amino acids are not metabolized by the plant, and (v) the exuded amino acids do not inhibit further exudation. This calculation yields an estimated root volume of $80 \cdot \pi \cdot 0.5^{2}=$ $63 \mathrm{~mm}^{3}$. The volume of root plus rhizosphere would then be $80 \cdot \pi \cdot 1.5^{2}=567 \mathrm{~mm}^{3}$. The volume of rhizosphere of one plant would then be $567-63 \approx 500 \mathrm{~mm}^{3}$. The 80 plants used would have a total rhizosphere volume of $40,320 \mathrm{~mm}^{3}$, or about $40 \mathrm{ml}$. According to this calculation the concentrations of individual amino acids in the rhizosphere would be twice the concentration found in the volume of $80 \mathrm{ml}$ of analyzed exudate, i.e., below $10 \mu \mathrm{M}$ (Table 1). Considering that the concentration of amino acid required for growth of an auxotroph in minimal medium is usually around $200 \mu \mathrm{M}$, this result suggested to us that the amino acid concentration found in exudate is insufficient to contribute substantially to the nutrition of rhizosphere bacteria.

To test this notion experimentally, amino acid auxotrophic mutants were constructed.

Table 1. Amino acid composition of axenically collected tomato root exudate

\begin{tabular}{lcc}
\hline Amino acid & $\begin{array}{c}\text { Determined concen- } \\
\text { tration in root exudate } \\
(\boldsymbol{\mu} \mathbf{M})^{\mathbf{y}}\end{array}$ & $\begin{array}{c}\text { Estimated concentra- } \\
\text { tion in rhizosphere } \\
(\boldsymbol{\mu M})^{\mathbf{z}}\end{array}$ \\
\hline Aspartic acid & 3.8 & 8 \\
Glutamic acid & 4.8 & 9 \\
Serine + asparagine & 1.3 & 3 \\
Glycine + glutamine & 1.2 & 3 \\
Histidine & 1.2 & 3 \\
Arginine + threonine & 1.1 & 2 \\
Isoleucine & 2.2 & 5 \\
Leucine & 2.5 & 5 \\
Phenylalanine & 1.2 & 2 \\
Lysine & 2.0 & 4 \\
\hline
\end{tabular}

${ }^{y}$ Amino acids not detected in exudate: alanine, proline, tyrosine, valine, methionine, and cysteine. Concentrations of these compounds in exudate therefore are below the detection limit of approximately $1 \mu \mathrm{M}$.

${ }^{\mathrm{z}}$ For assumptions used in these estimates, see Results.

\section{Isolation and characterization of amino acid auxotrophic mutants.}

Screening of 10,000 P. fluorescens strain WCS365:: $\mathrm{Tn} 5$ lac Z colonies yielded 40 auxotrophic mutants $(0.4 \%)$ that grew on KB but not on SSM. Analysis of these mutants by growth on SSM supplemented with various mixtures of compounds as described by Holliday (1956) showed that the auxotrophy of 12 mutants could not be identified by this method. These mutants were not used further. Mutants requiring tryptophan (PCL1009), arginine (PCL1033), valine plus isoleucine (PCL1022), leucine (PCL1014), and histidine (PCL1003) were selected for further use in colonization experiments.

\section{Tomato rhizosphere colonization of amino acid auxotrophic mutants.}

The ability of each auxotrophic mutant to reach the tip of the root system after inoculation of the seedling was determined in the absence (Table 2) and presence (Table 3) of the

Table 2. Colonization of tomato root tip by Pseudomonas fluorescens strain WCS365 and selected amino acid auxotrophic Tn5lacZ mutants inoculated as single strains in gnotobiotic system, in absence and presence of exogenously added amino acids ${ }^{y}$

\begin{tabular}{|c|c|c|c|c|c|c|}
\hline \multirow[b]{2}{*}{ Addition to PNS $^{\mathbf{z}}$} & \multicolumn{6}{|c|}{ Colonization $\left[\log _{10}(\mathrm{CFU}+1) / \mathrm{cm}\right.$ root tip] by strain } \\
\hline & $\begin{array}{c}\text { WCS3 } \\
65\end{array}$ & $\begin{array}{l}\text { PCL } \\
1014 \\
(\text { leu })\end{array}$ & $\begin{array}{l}\text { PCL } \\
1033 \\
(\text { arg })\end{array}$ & $\begin{array}{l}\text { PCL } \\
1003 \\
\text { (his) }\end{array}$ & $\begin{array}{l}\text { PCL } \\
1022 \\
\text { (ilv) }\end{array}$ & $\begin{array}{l}\text { PCL } \\
1009 \\
(\text { trp })\end{array}$ \\
\hline None & $2.8 \mathrm{a}$ & $0 \mathrm{c}$ & $0 \mathrm{c}$ & $0 \mathrm{c}$ & $0 \mathrm{c}$ & $0 \mathrm{c}$ \\
\hline Leucine & $2.1 \mathrm{a}$ & $2.7 \mathrm{a}$ & & $\ldots$ & & $\ldots$ \\
\hline Arginine & $4.3 \mathrm{~b}$ & & $2.8 \mathrm{a}$ & & & \\
\hline Histidine & $4.4 \mathrm{~b}$ & & $\ldots$ & $4.0 \mathrm{~b}$ & & \\
\hline Valine + isoleucine & e $\quad 2.4 \mathrm{a}$ & & $\ldots$ & $\ldots$ & $2.9 \mathrm{a}$ & \\
\hline Tryptophan & $5.1 \mathrm{~b}$ & & $\ldots$ & $\ldots$ & $\ldots$ & $5.8 \mathrm{~b}$ \\
\hline \multicolumn{7}{|c|}{$\begin{array}{l}\text { y Sterile, germinated tomato seeds were dipped in a } 10^{7} \mathrm{CFU} / \mathrm{ml} \text { suspen- } \\
\text { sion of cells of WCS365 or an auxotrophic WCS365::Tn5lacZ mu- } \\
\text { tants. After } 7 \text { days of plant growth, root tip was isolated. Bacteria were } \\
\text { isolated from root tip and plated on King's medium B, supplemented } \\
\text { with X-gal, in order to differentiate wild-type (white) and mutant } \\
\text { (blue) colonies on a single plate. From these numbers, the } \log _{10}(\mathrm{CFU}+ \\
1) / \mathrm{cm} \text { value was calculated. Values represent averages of } 10 \text { plants. } \\
\text { Detection limit for each determination is } 2.4 \mathrm{log} \text { CFU/cm root tip or } \\
0.24 \text { log CFU/ml for } 10 \text { plants. Values with same letter are not signifi- } \\
\text { cantly different }(P=0.05 \text { ) according to Wilcoxon-Mann-Whitney test. } \\
{ }^{\mathrm{z}} \text { Plant nutrient solution. }\end{array}$} \\
\hline
\end{tabular}

Table 3. Colonization of tomato root tip by auxotrophic Tn5lacZ mutants of Pseudomonas fluorescens strain WCS365 after co-inoculation with wild-type cells in gnotobiotic system, in absence and presence of exogenously added amino acids ${ }^{y}$

\begin{tabular}{|c|c|c|c|c|c|c|}
\hline \multirow[b]{2}{*}{ Addition to PNS $^{\mathbf{z}}$} & \multicolumn{6}{|c|}{ Colonization $\left[\log _{10}(\mathrm{CFU}+1) / \mathrm{cm}\right.$ root tip] by strain } \\
\hline & $\begin{array}{c}\text { WCS3 } \\
65\end{array}$ & $\begin{array}{l}\text { PCL } \\
1014 \\
(\text { leu })\end{array}$ & $\begin{array}{l}\text { PCL } \\
1033 \\
\text { (arg) }\end{array}$ & $\begin{array}{l}\text { PCL } \\
1003 \\
\text { (his) }\end{array}$ & $\begin{array}{l}\text { PCL } \\
1022 \\
\text { (ilv) }\end{array}$ & $\begin{array}{l}\text { PCL } \\
1009 \\
\text { (trp) }\end{array}$ \\
\hline None & $3.3 \mathrm{a}$ & $0 \mathrm{c}$ & $0 \mathrm{c}$ & $0 \mathrm{c}$ & $0 \mathrm{c}$ & $0 \mathrm{c}$ \\
\hline Leucine & $5.0 \mathrm{~b}$ & $5.2 \mathrm{~b}$ & & .. & . & \\
\hline Arginine & $4.4 \mathrm{~b}$ & $\ldots$ & $1.4 \mathrm{~d}$ & & . & \\
\hline Histidine & $3.6 \mathrm{a}$ & $\ldots$ & $\ldots$ & $2.9 \mathrm{a}$ & & \\
\hline Valine + isoleucine & $2.2 \mathrm{a}$ & $\ldots$ & $\ldots$ & $\ldots$ & $3.4 \mathrm{a}$ & \\
\hline Tryptophan & $5.1 \mathrm{~b}$ & $\ldots$ & $\ldots$ & $\ldots$ & $\ldots$ & $4.9 \mathrm{~b}$ \\
\hline
\end{tabular}

${ }^{y}$ For description of colonization assay, see Table 2 footnote. In the experiments described here, seedlings were co-inoculated a 1:1 mixture of $10^{7} \mathrm{CFU} / \mathrm{ml}$ of $P$. fluorescens strain WCS365 and an auxotrophic WCS365::Tn5lacZ mutant. Values with same letter are not significantly different $(P=0.05)$ according to Wilcoxon-Mann-Whitney test.

${ }^{\mathrm{z}}$ Plant nutrient solution. 
wild-type strain and in the absence and presence of the required amino acid. When mutant and wild type were tested separately, sterile tomato seedlings were inoculated in a suspension of approximately $10^{7} \mathrm{CFU} / \mathrm{ml}$ of the single strain. In the case of mixtures, seedlings were inoculated in a $1: 1 \mathrm{mix}-$ ture of mutant and wild type containing a total of $10^{7} \mathrm{CFU} / \mathrm{ml}$. With this method, tomato seedlings contained approximately 5 $\times 10^{4} \mathrm{CFU}$ directly after inoculation. After 7 days of plant growth, the root tip was isolated and the number of CFU was determined for each strain on KB supplemented with X-gal. The results show that none of the auxotrophic mutants colonized the root tips after inoculation, neither alone (Table 2) nor in competition with the wild-type strain (Table 3).

Addition of the required amino acid restored colonization by the mutants when tested alone (Table 2), as well as after co-inoculation with the wild-type strain (Table 3). Addition of the individual amino acids often appeared to affect the level of colonization by the wild-type strain (Tables 2 and 3). This trend was usually followed by the mutants except for the arginine-requiring mutant PCL1033, which never reached the corresponding wild-type level (Tables 2 and 3). Inspection of the plants showed that the addition of tryptophan to the plant growth medium caused shorter and somewhat thicker plant roots.

Analysis of other parts of the root showed that auxotrophic mutants were rarely present on root parts below the first centimeter of the root base. On 1-cm segments below the root base, the wild-type strain was present in numbers that were also found in previous studies, approximately $10^{6} \mathrm{CFU} / \mathrm{cm}$ (Simons et al. 1996). On the root base (i.e., the part that was

Table 4. Bacterial strains and relevant characteristics

\begin{tabular}{|c|c|c|}
\hline Strain & Relevant characteristics & Reference or source \\
\hline \multicolumn{3}{|c|}{ Escherichia coli } \\
\hline S17-1 & $\begin{array}{l}\text { MM294, RP4-2 Tc::Mu- } \\
\text { Km::Tn7 chromosomally } \\
\text { integrated }\end{array}$ & Simon et al. 1983 \\
\hline \multicolumn{3}{|l|}{ Pseudomonas } \\
\hline \multirow[t]{4}{*}{ WCS365 } & $\begin{array}{l}\text { Wild-type } P \text {. fluorescens, } \\
\text { isolated from potato roots }\end{array}$ & $\begin{array}{l}\text { Geels and Schippers } \\
1983\end{array}$ \\
\hline & $\begin{array}{l}\text { Efficient colonizer of the } \\
\text { potato rhizosphere }\end{array}$ & Brand et al. 1990 \\
\hline & $\begin{array}{l}\text { Efficient colonizer of the } \\
\text { tomato, radish, and wheat } \\
\text { rhizosphere }\end{array}$ & Simons et al. 1996 \\
\hline & $\begin{array}{l}\text { Biocontrol strain in hydro- } \\
\text { ponic cucumber system }\end{array}$ & J. Postma, unpublished \\
\hline PCL1003 & $\begin{array}{l}\text { WCS365::Tn5lacZ, re- } \\
\text { quiring histidine }\end{array}$ & This work \\
\hline PCL1009 & $\begin{array}{l}\text { WCS365::Tn5lacZ, re- } \\
\text { quiring tryptophan }\end{array}$ & This work \\
\hline PCL1014 & $\begin{array}{l}\text { WCS365::Tn5lacZ, re- } \\
\text { quiring leucine }\end{array}$ & This work \\
\hline PCL1022 & $\begin{array}{l}\text { WCS365::Tn5lacZ, re- } \\
\text { quiring isoleucine and } \\
\text { valine }\end{array}$ & This work \\
\hline PCL1033 & $\begin{array}{l}\text { WCS365::Tn } 5 \text { lacZ, re- } \\
\text { quiring arginine }\end{array}$ & This work \\
\hline \multicolumn{3}{|l|}{ Plasmid } \\
\hline pCIB 100 & $\begin{array}{l}\text { pLRK } \Delta 211 \text { (ColE1) with } \\
\text { pSUP5011 mobilization } \\
\text { segment. Carries Tn5lacZ } \\
\left(\mathrm{Km}^{\mathrm{r}}\right) \text {. The } \text { lacZ is con- } \\
\text { stitutively expressed in } \\
\text { Pseudomonas. }\end{array}$ & Lam et al. 1990 \\
\hline
\end{tabular}

inoculated), the number of cells of both wild type and mutant were approximately $10^{6}$ to $5 \times 10^{6} \mathrm{CFU} / \mathrm{cm}$ after 7 days of plant growth. The total number of wild-type bacteria on the root was about $5 \times 10^{6}$.

\section{DISCUSSION}

The amino acid analysis of tomato root exudate (Table 1) shows that many amino acids are present. All major peaks in the chromatograms could be identified as known amino acids.

The amounts we found correspond, with respect to order of magnitude, to the work of others on root exudate amino acids (van Egeraat 1972; Klein et al. 1988; Gamliel and Katan 1992a). We found amino acid concentrations in the micromolar range, in 7-day-old sterile exudate and with $0.5 \mathrm{ml}$ of PNS per tomato plant. We considered it unlikely that the low amounts of amino acids we found can function as major nutrients for rhizosphere-colonizing micro-organisms (see estimate in Results section). This notion was tested by an in situ assay in the rhizosphere, i.e. colonization, based on previous work on tomato rhizosphere colonization (Simons et al. 1996). This work indicated that the most sensitive assay for putative colonization mutants is the analysis of the lower root parts, i.e., the root tip.

Our results on tomato root tip colonization by five amino acid auxotrophic mutants show that the mutants do not colonize the root tip unless the required amino acid is added (Tables 2 and 3). We do not understand the effects usually found, after the addition of amino acids, on bacterial numbers of both the wild-type strain and mutants. Since colonized roots generally show a decreasing number of bacteria from root base to root tip (Simons et al. 1996), the increased colonization observed in the presence of tryptophan may be explained by the shorter roots.

Restoration of colonization by the addition of the required amino acid, as observed in most experiments (Tables 2 and 3), shows that the colonization defect is due to the lack of the amino acid. The colonization results (Tables 2 and 3 ) therefore confirm our notion (Table 1 and text) that the amount of amino acids in exudate is too low to contribute substantially to supporting growth of strain WCS365 in the rhizosphere. Inoculant bacteria may use a survival strategy in the rhizosphere that requires the expression of specific genes (Matin 1992). The possibility was considered that insufficient amino acid is available for the auxotrophic mutants to produce these proteins and that they therefore cannot survive, let alone grow. However, considering the number of cells actually present on a freshly inoculated seedling, approximately $5 \times 10^{4}$, the 100 fold higher number we isolated from the root base after 1 week indicates that substantial growth of the bacteria occurs in the rhizosphere. The number of cells of auxotrophic mutants on the root base after 7 days is usually equal to or not more than five-fold lower than the numbers of wild-type cells, which indicates that these cells must have grown. Usually, no auxotrophic cells can be detected at the lower root parts after 7 days of plant growth. Apparently, the mutants cannot take part in the actual colonization process.

The observation of Glandorf (1992), using mutants provided by our group, that amino acid auxotrophs of strain WCS365 are also impaired in potato root colonization tested in field soil, indicates that our results can also be valid in 
other systems. Our results add one important trait to the known bacterial traits required for efficient rhizosphere colonization by fluorescent pseudomonads. To these traits, namely, motility (de Weger et al. 1987), chemotaxis (Gamliel and Katan 1992b), the production of the O-antigenic side chain of lipopolysaccharide (de Weger et al. 1989), the ability to synthesize vitamin B1, and a high bacterial growth rate (Simons et al. 1996), we can now add amino acid prototrophy.

\section{MATERIALS AND METHODS}

\section{Bacterial strains and growth conditions.}

Bacterial strains used in this study are shown in Table 4. $P$. fluorescens WCS365 was grown at $28^{\circ} \mathrm{C}$ on King's medium B (KB; King et al. 1954) solidified with $1.8 \%$ agar (Bacto Agar, Difco Inc., Detroit, MI). A derivative of Escherichia coli S171 harboring plasmid pCIB100, which is a suicide plasmid in Pseudomonas, was grown at $37^{\circ} \mathrm{C}$ on solidified LC medium (Maniatis et al. 1982) supplemented with $20 \mu \mathrm{g}$ of kanamycin (Sigma, Bornhem, Belgium) per ml. Stock cultures of all strains were kept in $35 \%$ glycerol at $-80^{\circ} \mathrm{C}$. Bacteria on agar were kept at $4^{\circ} \mathrm{C}$ until use.

$P$. fluorescens WCS365::Tn5lacZ transconjugants were generated by a two-parental mating of strains $P$. fluorescens WCS365 and E. coli S17-1 harboring plasmid pCIB100 (Lam et al. 1990) as described previously (Simons et al. 1996). Auxotrophic transconjugants were isolated after screening of WCS365::Tn5 colonies on standard succinate medium (SSM; Meyer and Abdallah 1978) and on KB. The auxotrophies of mutants that grew on KB but not on SSM were further characterized by the method of Holliday (Holliday 1956). Briefly, colonies were transferred to SSM plates containing specific amino acid mixtures. Mutants that grew on two of these plates require a single compound for growth, which was confirmed by determination of growth on SSM supplemented with the appropriate compound. Mutants that grew on only one plate containing a mixture of amino acids apparently need a combination of compounds. The latter mutants were further characterized by determination of growth on SSM supplemented with various mixtures of compounds that were present in the original mixture as described by Holliday (1956).

\section{Collection of root exudate.}

Tomato (Lycopersicon esculentum Mill. 'Carmello') seeds (S\&G Seeds B.V., Enkhuizen, The Netherlands) were sterilized by gentle shaking for $3 \mathrm{~min}$ in $5 \%$ household sodium hypochlorite. The sterilized seeds were soaked six times for 30 min in sterile, demineralized water. To synchronize the germination process, seeds were placed on petri plates containing PNS (plant nutrient solution, Hoffland 1992), consisting of 5 $\mathrm{mM} \mathrm{Ca}\left(\mathrm{NO}_{3}\right)_{2}, 5 \mathrm{mM} \mathrm{KNO}{ }_{3}, 2 \mathrm{mM} \mathrm{MgSO} 4,1 \mathrm{mM} \mathrm{KH}_{2} \mathrm{PO}_{4}$, and micronutrients, solidified with $1.5 \%$ Pronarose D1 (Hispanagar, Burgos, Spain). The plates were incubated overnight upside down in the dark at $4^{\circ} \mathrm{C}$, followed by incubation at $28^{\circ} \mathrm{C}$ for 2 days. Root exudate was collected in Magenta vessels (Sigma, Bornhem, Belgium), equipped with a stainless steel, perforated tray and filled with a volume of $80 \mathrm{ml}$ of PNS up to the tray. Eighty germinated seedlings were placed on the tray with their roots into the solution. After 1 week of growth at $18^{\circ} \mathrm{C}$, exudate was collected by filtration over Whatman No. 3 filter paper (Whatman International Ltd., Maidstone,
England) to remove solid plant material, and frozen immediately with liquid nitrogen. A sample of exudate was taken directly from the Magenta vessels and tested for sterility on solidified KB. The exudate was then lyophilized and the solid material was redissolved in $2.0 \mathrm{ml}$ of demineralized water. This 40-fold concentrated exudate was filtered through a 0.45 $\mu \mathrm{m}$ disposable cellulose-nitrate filter (Sartorius $\mathrm{GmbH}$, Göttingen, Germany) to remove undissolved particles, and stored at $-20^{\circ} \mathrm{C}$ until use. Only material from exudates in which no microbial growth could be detected was used.

\section{Amino acid isolation and analysis.}

Root exudate amino acids were trapped on a Dowex AG50W-X8 cation exchanger (Biorad, Veenendaal, The Netherlands), according to the method of Klein et al. (1988). Before use, the resin was washed and equilibrated by subsequent washings with $0.5 \mathrm{M}$ ammonium sulfate for $2 \mathrm{~h}$ and $7 \%$ formic acid for $8 \mathrm{~h}$. The resin was finally rinsed with and stored in $1.0 \%$ formic acid. A disposable column (EconoPac, Biorad, Veenendaal, The Netherlands) was filled with $20 \mathrm{ml}$ of cation exchanger and washed with $80 \mathrm{ml}$ of $1.0 \%$ formic acid (Sigma), followed by demineralized water until the eluent was neutral. The exudate sample was loaded on this column, and washed with $2.0 \mathrm{ml}$ of $1 \mathrm{mM} \mathrm{HCl}$. The neutral and negatively charged compounds were washed off with four column volumes of $50 \mathrm{mM} \mathrm{HCl}$. Subsequently, the trapped amino acids were eluted with four column volumes of $4 \mathrm{M}$ ammonium hydroxide. The resulting solution was freed from ammonia overnight in vacuo with a cold trap and subsequently lyophilized. Prior to HPLC analysis the samples were derivatized with PITC (phenylisothiocyanate; Pierce, Rockford, IL) (Janssen et al. 1986). Briefly, lyophilized samples from the cation exchanger were dissolved in the redrying mix EMT (ethanol-Milly Q water-triethylamine, 2:2:1, vol/vol/vol). Dissolved samples were dried in a Speedvac concentrator for $30 \mathrm{~min}$. This procedure was conducted two times. Subsequently, $20 \mu \mathrm{l}$ of freshly prepared PEMT (PITC-EMT, 1:7:1:1 $\mathrm{vol} / \mathrm{vol} / \mathrm{vol} / \mathrm{vol}$ ) derivatization mixture was added. After the sample was carefully dissolved, the mixture was allowed to react at ambient temperature for $20 \mathrm{~min}$. After drying in a Speedvac concentrator, the sample was dissolved in $400 \mu$ of buffer A (0.14 M sodium acetate, $0.05 \%$ TEA [triethylamine; Sigma, Bornhem, Belgium], 4\% acetonitrile in Milly Q water; adjusted to $\mathrm{pH} 6.40$ with acetic acid) prior to injection on the column. The HPLC system consisted of a $\mathrm{C}_{18}$ reversed-phase column (Shandon hypersil ODS $250 \cdot 4 \mathrm{~mm}$, Shandon BV, Zeist, The Netherlands) at $50^{\circ} \mathrm{C}$ in a column oven and gradient elution with buffer A and buffer B (60\% acetonitrile in water). Even with an optimized gradient, amino acids eluted in clusters, as has been observed by others (Findlay and Geishow 1986). Ornithine was used as an internal standard. A standard mixture of amino acids (Pierce amino acid standards mixH nr.20088) was used as an external standard. This mixture contains alanine, arginine, aspartic acid, cysteic acid, glutamic acid, glycine, histidine, isoleucine, lysine, methionine, phenylalanine, proline, serine, threonine, tyrosine, and valine. With known concentrations of the standard amino acids, exudate amino acid concentrations were corrected for losses during the isolation and derivatization procedure. For peak detection the variable wavelength monitor (Pharmacia LKB, Uppsala, Sweden) was set to $254 \mathrm{~nm}$. Nelson 2600 / 
HPLC Manager software (Pharmacia) was used for peak integration and identification.

Amino acids used for peak identification (amino acid standard kit 22, Pierce nr. 20065) were derivatized individually and analyzed in couples to determine elution volumes. A mixture of external standards was used between runs to determine elution volume of appropriate peaks. Peaks were identified on the basis of elution volumes and by mixing samples with known amino acids.

\section{Gnotobiotic colonization assay.}

For studying the colonization of the rhizosphere a recently developed gnotobiotic tube system for tomato was used (Simons et al. 1996). Briefly, quartz sand (Wessem filterzand, Wessem, The Netherlands) was mixed with PNS (10\% vol/ $\mathrm{wt}$ ), $\mathrm{pH}$ 5.8. If required, $1 \mathrm{mM}$ amino acid (Pierce amino acid standard kit $22 \mathrm{nr}$. 20065) was added to the PNS. The complete tube was sterilized by autoclaving at $110^{\circ} \mathrm{C}$ for $40 \mathrm{~min}$. After autoclaving, the tubes were stored at room temperature for at least $48 \mathrm{~h}$ to equilibrate. Inoculation of tomato seeds was performed by dipping germinated seeds for $5 \mathrm{~min}$ in a bacterial suspension of $10^{7} \mathrm{CFU} / \mathrm{ml}$. After inoculation, the seeds were placed under the surface of the quartz sand with sterile forceps. The plant growth tubes were kept in a climatecontrolled growth chamber $\left(18^{\circ} \mathrm{C}, 70 \%\right.$ relative humidity, $16 \mathrm{~h}$ daylight) to allow the tomato plantlets to grow. After 7 days, in which the root systems grew to an average length of $8 \mathrm{~cm}$, a $1-\mathrm{cm}$ fragment was cut off the root tip and shaken vigorously in $1.0 \mathrm{ml}$ of PNS on an Eppendorf shaker for $15 \mathrm{~min}$ to remove the bacteria. The bacterial suspension was diluted 10fold and $37 \mu \mathrm{l}$ was plated on KB plates supplemented with 40 $\mu \mathrm{g}$ of X-gal per ml, with an spiral plater (Spiral Systems Inc., Cincinnati, OH). After 2 days of incubation at $28^{\circ} \mathrm{C}$ the numbers of yellow/white (wild-type) and blue (Tn5lacZ auxotrophic mutants) colonies were counted. The $\mathrm{CFU} / \mathrm{cm}$ was calculated (Davies and Whitbread 1989), $\log _{10}(\mathrm{CFU}+1) / \mathrm{cm}$ transformed (Loper and Schroth 1984) to avoid the nonexistent $\log (0)$ situation. Estimates of mean and standard deviation were calculated, to be used as point estimates. All colonization experiments were carried out in 10-fold, and repeated at least once. For statistical comparison of strains in mixed inocula the nonparametric Wilcoxon-Mann-Whitney test was used (Siegel 1956; Sokal and Rohlf 1981).

\section{ACKNOWLEDGEMENTS}

Financial support was obtained from the EU-BIOTECH program (contract no. BIO2-CT93-0196). We wish to thank E. Meelis of the Institute of Evolutionary and Ecological Sciences for valuable advice on statistics, J. Bodlaender and Th. B. van Vliet for their help with the setup of the HPLC amino acid analysis system, and R. Scheffer (S\&G Seeds B.V., Enkhuizen, The Netherlands) for supplying tomato seeds.

\section{LITERATURE CITED}

Brand, J., Lugtenberg, B. J. J., Glandorf, D. C. M., Bakker, P. A. H. M., Schippers, B., and de Weger, L. A. 1990. Isolation and characterization of a superior potato root-colonizing Pseudomonas strain. Pages 350-354 in: Plant growth promoting rhizobacteria - progress and prospects. IOBC/WPRS Bull. XIV-8. C. Keel, B. Koller, and G. Défago, eds. Interlaken, Switzerland.

Davies, K. G., and Whitbread, R. 1989. A comparison of methods for measuring the colonisation of a root system by fluorescent pseudomonads. Plant Soil 116:239-246. de Weger, L. A., van der Vlugt, C. I. M., Wijfjes, A. H. M., Bakker, P. A. H. M., Schippers, B., and Lugtenberg, B. 1987. Flagella of a plantgrowth-stimulating Pseudomonas fluorescens are required for colonization of potato roots. J. Bacteriol. 169:2769-2773.

de Weger, L. A., Bakker, P. A. H. M., Schippers, B., van Loosdrecht, M. C. M., and Lugtenberg, B. J. J. 1989. Pseudomonas spp. with mutational changes in the $\mathrm{O}$-antigenic side chain of their lipopolysaccharide are affected in their ability to colonize potato roots. Pages 197202 in: NATO ASI Series, Vol. H36. B. J. J. Lugtenberg, ed. SpringerVerlag, Berlin.

Findlay, J. B. C., and Geishow, M. J. 1986. Protein Sequencing: A Practical Approach, IRL Press, Oxford.

Gamliel, A., and Katan, J. 1992a. Influence of seed and root exudates on fluorescent pseudomonads and fungi in solarized soil. Phytopathology 82:320-327.

Gamliel, A., and Katan, J. 1992b. Chemotaxis of fluorescent pseudomonads towards seed exudates and germinating seeds in solarized soil. Phytopathology 82:328-332.

Geels, F. P., and Schippers, B. 1983. Selection of antagonistic fluorescent Pseudomonas spp. and their root colonization and persistence following treatment of seed potatoes. Phytopathol. Z. 108:193-206.

Glandorf, D. C. M. 1992. Root colonization by fluorescent pseudomonads. Ph.D. thesis. University of Utrecht, Utrecht, The Netherlands.

Hiltner, L. 1904. Uber neue Erfahrungen und Probleme auf dem Gebiete der Bodenbakteriologie. Arb. Dtsch. Landwirtsch. Ges. 98:59-78.

Hoffland, E. 1992. Quantitative evaluation of the role of organic acid exudation in the mobilization of rock phosphate by rape. Plant Soil 140:279-289.

Holliday, R. 1956. A new method for the identification of biochemical mutants of micro-organisms. Nature 178:987

Janssen, P. S. L., van Nispen, J. W., Melgers, P. A. T. A., Bogaart, H. W. M., Hamelinck, R. L. A. E., and Goverde, B. C. 1986. HPLC analysis of phenylthiocarbamyl (PTC) amino acids I. Evaluation and optimization of the procedure. Chromatographia 22:354-350.

King, E. O., Ward, M. K., and Raney, D. E. 1954. Two simple media for the demonstration of pyocyanin and fluorescin. J. Lab. Clin. Med. 44: 301-307.

Klein, D. A., Frederick, B. A., Biondini, M., and Trlica, M. J. 1988. Rhizosphere microorganism effects on soluble amino acids, sugars and organic acids in the root zone of Agropyron cristatum, A. Smithii and Bouteloua gracilis. Plant Soil 110:19-25.

Lam, S. T., Ellis, D. M., and Ligon, J. M. 1990. Genetic approaches for studying rhizosphere colonization. Plant Soil 129:11-18.

Loper, J. E., Suslow, T. V., and Schroth, M. N. 1984. Lognormal distribution of bacterial populations in the rhizosphere. Phytopathology 74:1454-1460.

Lynch, J. M., and Whipps, J. M. 1990. Substrate flow in the rhizosphere. Plant Soil 129:1-10.

Maniatis, T. A., Fritsch, E. F., and Sambrook, J. 1982. Molecular Cloning: A Laboratory Manual. Cold Spring Harbor Laboratory, Cold Spring Harbor, NY.

Matin, A. 1992. Genetics of bacterial stress response and its applications. Ann. N.Y. Acad. Sci. 665:1-15.

Meyer, J. M., and Abdallah, M. A. 1978. The fluorescent pigment of Pseudomonas fluorescens: Biosynthesis, purification and physiochemical properties. J. Gen. Microbiol. 107:319-328.

Schippers, B., Bakker, A. W., and Bakker, P. A. H. M. 1987. Interactions of deleterious and beneficial rhizosphere microorganisms and the effect of cropping practices. Annu. Rev. Phytopathol. 25:339-358.

Siegel, S. 1956. Nonparametric Statistics for the Behavioral Sciences. McGraw-Hill, New York. pp.116-126.

Simon, R., Priefer, U., and Pühler, A. 1983. A broad host range mobilization system for in vivo genetic engineering: Transposon mutagenesis in Gram-negative bacteria. Biotechnology 1:784-791.

Simons, M., van der Bij, A. J., Brand, I., de Weger, L. A., Wijffelman, C. A., and Lugtenberg, B. J. J. 1996. Gnotobiotic system for studying rhizosphere colonization by plant growth-promoting Pseudomonas bacteria. Mol. Plant-Microbe Interact. 9:600-607.

Sokal, R. R., and Rohlf, F. J. 1981. Biometry. Freeman and Co., San Francisco.

van Egeraat, A. W. S. M. 1972. Pea root exudates and their effect upon root-nodule bacteria. Ph.D. thesis. Agricultural University, Wageningen, The Netherlands.

Weller, D. M. 1988. Biological control of soilborne plant pathogens in the rhizosphere with bacteria. Annu. Rev. Phytopathol. 26:379-407. 